\title{
Using Observed Warming to Identify Hazards to Mozambique Maize Production
}

\section{Conclusions}

\section{New Perspectives on Crop Yield Constraints because of Climate Change}

Climate change impact assessments usually focus on changes to precipitation because most global food production is from rainfed cropping systems; however, other aspects of climate change may affect crop growth and potential yields.

A recent (2011) study by the University of California, Santa Barbara (UCSB) Climate Hazards Group, determined that climate change may be affecting Mozambique's primary food crop in a usually overlooked, but potentially significant way (Harrison and others, 2011). The study focused on the direct relation between maize crop development and growing season temperature. It determined that warming during the past three decades in Mozambique may be causing more frequent crop stress and yield reductions in that country's maize crop, independent of any changes occurring in rainfall. This report summarizes the findings and conclusions of that study.
- Recent (2011) analysis indicates that 30 years of substantial warming has increased temperatures during the primary growing season in central Mozambique by $\sim 1.5$ degrees Celsius.

- The warming is affecting the maize crop's phenology by causing an onset of flowering 4 days earlier and a 5 to 7 percent decline in total time to plant maturation.

- Warmer temperatures earlier in the season threaten maize yields by exposing the plant at sensitive crop phases to increased heat and drought, and shortening the crop's growth cycle, thus reducing the size of the plant and the weight of its grains.

- Continued warming could increase the risk of these hazards and affect crop production, regardless of any changes in rainfall.

\section{Assessing Changes in Temperature and Maize} Development in Mozambique

The Harrison (2011) study analyzed historical changes in air temperature in Mozambique between 1979 and 2008, and collected data that relate the duration of specific maize plant growth phases to differing temperatures. Mozambique-specific planting dates were estimated using the U.S. Geological Survey (USGS) Geospatial Water Requirement Satisfaction Index (GeoWRSI.) The following changes in maize growth stages were assessed at nine locations (fig. 1):

- number of days from planting to flowering;

- duration of the reproductive period (flowering to maturity, days);

- total growth duration (planting to maturity, days);

- minimum, maximum, and average temperature during each of these periods, in degrees Celsius $\left({ }^{\circ} \mathrm{C}\right)$; and

- 90th percentile maximum temperature during the reproductive period $\left({ }^{\circ} \mathrm{C}\right)$.

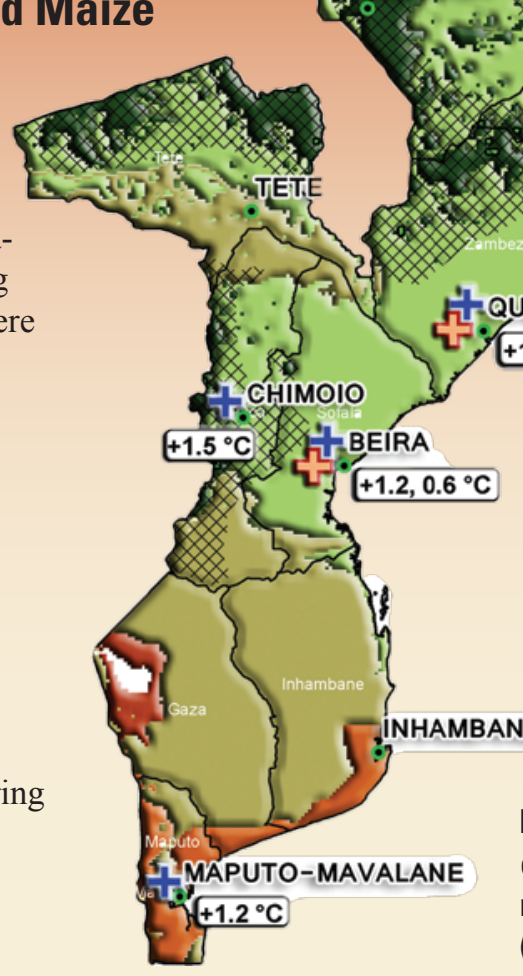
changes in growing season mean minimum and maximum temperature (1979-80 to 2008-09). (Harrison and others, 2011). 
In most locations, the dominant changes in temperature patterns related to maize plant growth phases were temperature increases during the early part of the growing season, from planting until flowering. Because maize growth is extremely responsive to temperatures, this caused a change in the onset of flowering, advancing it by an average of 4 days in 6 of the 9 locations since 1979. Changes of up to 6 days were identified at central region locations (Nampula, Beira, Chimoio, and Quelimane, fig. 1) where average temperatures during the early season increased by more than $1.5^{\circ} \mathrm{C}$. In Nampula, the maximum temperature during this period increased by $2 \cdot 4^{\circ} \mathrm{C}$. Increases in an area's minimum daily temperature were determined to be particularly indicative of changes in growth phases at most sites (fig. $2 A$ ).

Statistically significant but less intense warming was identified throughout the entire maize growth period in Mozambique, which adds to the decreases evident in the time to maize maturity (figs. 2B,C). Warming during the latter part of the growing season was strong enough to shorten the reproductive period by 5 percent in Quelimane and Nampula. During the reproductive period, the hottest daytime temperatures at three central Mozambique locations increased by as much as $1.8^{\circ} \mathrm{C}$, passing maize growth tolerance thresholds.

If identified warming patterns continue, Mozambique maize production could be threatened by the stress of hotter early season temperatures and by faster maturation. The central region appears most at risk. The warming-induced phenological changes the study identified, and the implications for maize yields are summarized in table 1 .

\section{How are Maize Yields Directly Affected by Warming Temperatures?}

Warming temperatures can alter maize yields in three main ways. Two of these involve changes in the plant's phenology, or the timing of its development stages. The third is more directfrom heat stress via exposure to excessive temperature.

\section{Maize Develops Faster at Increased Temperatures, and Yields are Strongly Related to the Duration of Certain Phases of Growth}

Maize phenology primarily is driven by temperature. From the seedling stage to maturity, plants mark the passing of time with thermally driven biological clocks. When the environment is warmer, the plants grow faster and at a predictable rate. For this reason, farmers have characterized their maize varieties for centuries by the "thermal-time" it takes to reach flowering and maturity, which are the most important stages of development. Two changes in crop phenology were identified as particularly significant in the Mozambique setting and time studied.

Time to maturity: Generally, the longer seasonal exposure a plant has to solar radiation (the fuel of photosynthesis) the larger the plant and the greater its yield. Observations indicate the greatest crop yields are obtained when relatively low
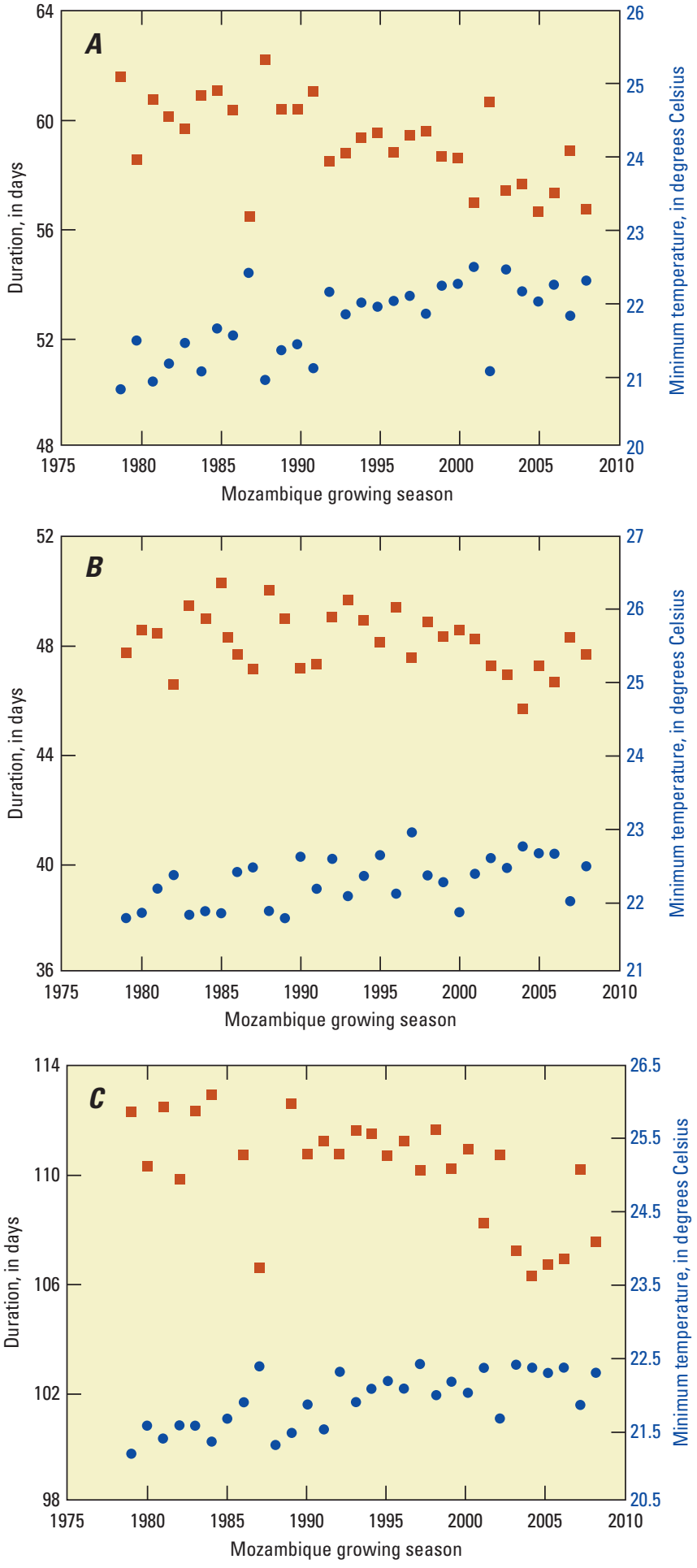

EXPLANATION

- Growth duration

- Minimum temperature

Figure 2. Historical trends of Mozambique maize growth duration and minimum temperature, stratified by phenological period: $A$, sowing to start of reproductive period; $B$, reproductive (grain filling) period; and $C$, sowing to physiological maturity (Harrison and others, 2011). 
Table 1. Statistically significant changes to maize phenology (1979-80 to 2008-09) at Mozambique stations and implications for maize production (Harrison and others, 2011).

\begin{tabular}{|c|c|c|c|}
\hline Phenological trend & Cause & Potential yield impact & Station \\
\hline $\begin{array}{l}\text { Decreased time from planting to start } \\
\text { of the reproductive period }\end{array}$ & Early season temperature increases & $\begin{array}{l}\text { Crop water requirements are at a } \\
\text { maximum earlier in the season; yield } \\
\text { risk if consistent rainfall does not also } \\
\text { start early }\end{array}$ & $\begin{array}{l}\text { Pemba } \\
\text { Nampula } \\
\text { Quelimane } \\
\text { Chimoio } \\
\text { Maputo }\end{array}$ \\
\hline $\begin{array}{l}\text { Decreased duration of the } \\
\text { reproductive period }\end{array}$ & $\begin{array}{l}\text { Mid- to late-season temperature } \\
\text { increases }\end{array}$ & Grain weight decreases; yield reduction & $\begin{array}{l}\text { Nampula } \\
\text { Quelimane }\end{array}$ \\
\hline Decreased time to maturity & $\begin{array}{l}\text { Temperature increases during } \\
\text { entire season }\end{array}$ & Plant biomass decreases; yield reduction & $\begin{array}{l}\text { Pemba } \\
\text { Nampula } \\
\text { Quelimane } \\
\text { Chimoio } \\
\text { Beira }\end{array}$ \\
\hline
\end{tabular}

temperature maximizes the duration of plant growth (Muchow and Bellamy, 1991). This helps explain why primary crop production zones are located in the coolest areas that have adequate rainfall. When other environmental variables remain unchanged, increased temperatures lower maize yields by reducing the time to plant maturity, the period over which most plant development occurs.

Reproductive period duration: Similarly, increased temperatures during a plant's reproductive period, when grain filling occurs, indirectly cause yield reductions. Yields are significantly correlated with the duration of the reproductive period (correlation of $r=0.81$; Cross, 1975). Temperatures control the duration of the period and the efficiency of the processes filling the grain. The rate of grain filling increases with warmer temperatures, but the duration of filling decreases. At extremely high temperatures, the rate of filling begins to decline. The overall result is that by accelerating a maize plant's development, increased temperatures decrease the reproductive period duration and prevent grains from reaching their potential size.

\section{Water or Heat Stress at Flowering also are Detrimental to Yield}

Water or heat stress at the time of a maize plant's flowering can directly reduce yields by disrupting pollination and the formation of maize grain. Yield reductions by as much as 7 percent per day of stress have been observed, making this development stage the most sensitive to drought and increased temperatures.

Warming temperatures can change the incidence of stress during flowering in two ways. The first is by directly increasing temperatures above a plant's tolerance levels (for maize, this is $30^{\circ} \mathrm{C}$ and greater). In regions with an already hot growing season, such as Mozambique, small amounts of additional warming can greatly increase this risk. Warmer temperatures also can speed plant development during the earlier part of the season, potentially causing the flowering stage to begin earlier.
This can be problematic because farmers tend to time their maize planting so that it reaches the flowering stage at the start of peak seasonal rainfall. Without accounting for warminginduced earlier flowering, farmers could find that stage occurring instead during hot and dry weather (fig. 3). Aligning a maize plant's reproductive phase with the peak of seasonal rainfall is important for maximal rainfed crop production. Continued warming may cause maize varieties to move out of phase with seasonal patterns of rainfall, threatening yields, especially if the silk-tasseling phase is subjected to hot, dry conditions.

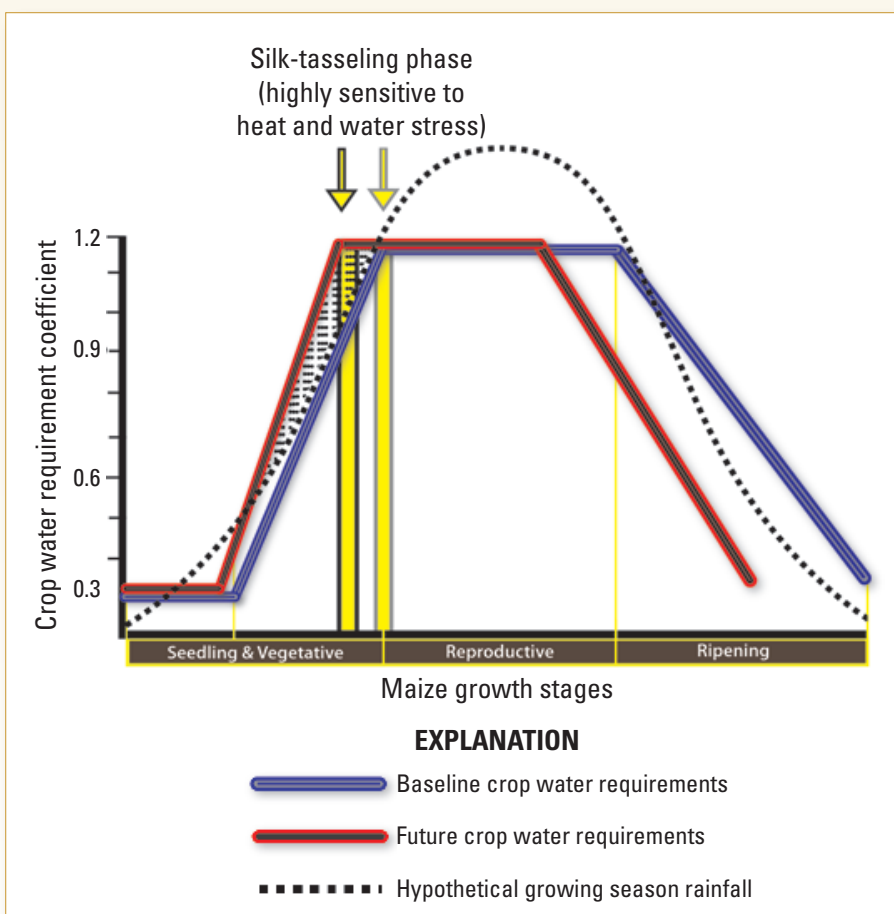

Figure 3. Maize growth stages and crop water requirements for historical and future growing season temperatures (Harrison and others, 2011). 


\section{Adapting Maize Production in Mozambique to Warmer Conditions}

This analysis identifies specific changes in climate in Mozambique that are probable to occur, and likely to continue, at least for the near future, and may have significant effects on food production if adaptation does not occur. These pieces of information can be used to increase climate resilience by guiding regionally appropriate adaptation strategies. Investments in climate adaptation may be most effective if applied on two primary fronts: at the local level, by communication with farmers, and at the sectoral level, by support for development and dissemination of climate-resilient plant-breeding and farmmanagement techniques. Neither strategy has to be complex or expensive.

\section{Simple and Inexpensive Climate Adaptation Strategies for Mozambique}

The Harrison study outlines several simple and regionally specific strategies that farmers could use to minimize future yield hazards associated with continuation of observed warming.

- Anticipate the early onset of flowering and delay planting by an equal length of time. This would lessen exposure to drought stress during the sensitive growth period and provide some escape from increased temperatures during the early part of the growing season.

- Plant maize varieties of longer growth duration than traditionally used. This would lengthen the otherwise shortened growth duration and prevent the associated problems.

Especially in already hot growing regions, the effect of warming on maize yields may be a serious issue over all of Africa. One study determined that for each day spent above $30^{\circ} \mathrm{C}$, final maize yield is reduced by 1 percent under optimal rainfed conditions, and by 1.7 percent under drought conditions (Lobell and others, 2011). A $1^{\circ} \mathrm{C}$ temperature increase would cause yields to decline in 65 percent of Africa's maize growing areas, even with optimal rainfall.

According to the concept of maize development and thermal-time, a spatially uniform increase in temperature would cause the largest phenological change in the coolest production regions, and affect yields by accelerating growth rate; however, in growing areas where temperatures already are close to plant threshold levels, even a small increase in temperature would induce heat stress. Because the nature of observed climate warming varies spatially and temporally, identifying the character of local warming is a key first step to identify the most likely form of local yield effects and to develop strategies for dealing with continued warming.

\section{References Cited}

Cross, H.Z., 1975, Diallel analysis of duration and rate of grain filling of seven inbred lines of corn: Crop Science, v. 15, p. 532-535.

Harrison, L., Michaelsen, J., Funk, C., and Husak, G., 2011, Effects of temperature changes on maize production in Mozambique: Climate Research, v. 46, p. 211-222. (Also available online at $h t t p: / / w w w . i n t-r e s . c o m / a b s t r a c t s / c r / v 46 /$ $n 3 /$.

Lobell, D.B., Banziger, M., Magorokosho, C., and Vivek, B., 2011, Nonlinear heat effects on African maize as evidenced by historical yield trials: Nature Climate Change, v. 1,

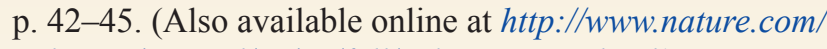
nclimate/journal/v1/n1/full/nclimate1043.html.)

Muchow, R.C., and Bellamy, J.A., eds., 1991, Climatic risk in crop production-Models and management for the semiarid tropics and subtropics: Wallingford, UK, CAB International, $548 \mathrm{p}$.

Additional information about climate change in Mozambique can be found in the 2009 National Institute for Disaster Management (INGC) Report at http://www.undp.org.mz/en/Publications/Other-Publications.

\section{Acknowledgments}

This report was written by Laura Harrison (UCSB, Geography), Chris Funk (USGS), and Gary Eilerts [U.S. Agency for International Development (USAID)]. It builds on a multi-year research project (see references) carried out under a USAID-funded FEWS NET agreement (AFP-P-00-03-00027-00) with USGS. Data, comments, and artistic support were kindly provided by Blessing Siwela, Tamuka Magadzire, John MacRobert, Libby White, Dr. Gregory Husak, and Professors Joel Michaelsen, Leila Carvalho, and Jennifer King.

Publishing support provided by Rolla Publishing Service Center. Maize photograph (ㄷ) Dan L. Perlman/EcoLibrary 2008. 